\title{
Dynamics of the Trade Balance: The Turkish J-Curve
}

\author{
Elif Akbostancı \\ Middle East Technical University \\ Department of Economics, 06531, Ankara, Turkey \\ elifa@metu.edu.tr
}

\begin{abstract}
The J-curve hypothesis suggests a specific pattern for the response of trade balance to real exchange rate changes: a real depreciation initially worsens the trade balance, but through time the trade balance improves, and thus the response of the trade balance over time generates a tilted $\mathrm{J}$ shape. This study investigates the existence of a J-curve in the Turkish data in the period of 1987-2000, by using quarterly data. First an error correction model is estimated to differentiate between the long-run equilibrium and short-run dynamics. Then the response of trade balance to real exchange rate shocks are investigated by using the generalized impulse response methodology. Even though the suggested long-run pattern, which is the improvement of the trade balance in response to a real depreciation emerges, our results do not exactly support the J-curve hypothesis in the short-run. In this study we found that the short-run behavior of the trade balance in response to real exchange rate shocks show an S-pattern reminiscent of the Backus et al (1994) rather than the J-curve pattern.
\end{abstract}

JEL Classification: F30, F32, F41 


\section{Dynamics of the Trade Balance: The Turkish J-Curve}

\section{Introduction}

The relationship between the trade balance and the real exchange rate attracted attention of the economists for some time. There is a popular belief that this relationship differs through time; that is the shortrun and the long-run responses of the trade balance will be different. It is suggested and widely believed that a real depreciation initially worsens the trade balance, but through time trade balance improves, and thus the response of trade balance over time generates a tilted $\mathrm{J}$ shape.

The textbook explanation of J-curve goes as follows; following a real depreciation volumes of exports and imports would not change much as the export and import contracts are usually made several months in advance. But the real depreciation will make the predetermined level of imports to cost more in domestic currency units, thus value of imports rise where the value of exports do not change much, which will worsen the trade balance immediately after the real depreciation. However as time passes by both producers and consumers will be more responsive and quantities start to adjust to the change in relative price of domestic goods and hence trade balance start to improve. The response of the trade balance through time than forms the famous J shape. Of course implicit in this discussion is the assumption that in the short-run elasticities are sufficiently low and in the long-run elasticities are sufficiently large, or in the long-run Marshall-Lerner condition holds.

The J-curve hypothesis generated a series of empirical research that investigated the existence of Jcurve both in the US data and other countries' data. The evidence on J-curve is mixed. Earlier studies like Krugman and Baldwin (1987) finds evidence of a J-curve in the US data. However in a series of papers Rose and Yellen (1989)(R\&Y from now on), Rose (1990) and (1991), not only the J-curve hypothesis is rejected, but also it is argued that there is no significant effect of the real exchange rate on the trade balance for both the developing and the developed countries, including the US.

In a more recent study by using the model introduced in R\&Y, Bahmani-Oskoee and Brooks (1999) used ARDL approach to US data and found that the short-run results support the R\&Y findings that is there is no effect of real exchange rate on the trade balance in the short run, but in the long-run the real depreciation of the US Dollar found to have a favorable effect on the trade balance. Wilson and Tat (2001) on the other hand again by using the R\&Y model find similar results as R\&Y for Singapore. However Singh (2002) models the trade 
balance ala Rose (1991) and by using an error correction model finds that trade balance of India is sensitive to real exchange rate changes as opposed to Rose (1990) and (1991).

In alternative approaches Koray and McMillin (1999) and Leonard and Stockman (2001) find positive evidence of J-curve. Koray and McMillin (1999) examined the response of real exchange rates and the trade balance to monetary policy shocks by using a VAR model. They find that a negative monetary shock initially improves the trade balance, which is correlated with an appreciation of the exchange rate, subsequently deteriorates, thus providing support for the J-curve hypothesis. Leonard and Stockman (2001) use nonparametric methods that allow for non-linearities to analyze the statistical relationship between current accounts, exchange rates and GDP. Their evidence supports the existence of J-curve in the data but not its standard explanation. They found that an increase in the current account is associated with a fall in GDP. This contradicts with the standard theoretical explanation that in the long-run trade balance improves after a depreciation through the increase in foreign demand improving the domestic GDP.

Rather than the J-curve, a few other papers talk about an S-curve in terms of the dynamic response of the trade balance. Backus, Kehoe and Kydland (1994) develop an international real business cycle model and find that the trade balance is counter cyclical and the cross correlation function of the trade balance and the terms of trade displays an S shape. Similarly Roberts (1995) in a dynamic model where import expenditure depends on wealth finds that besides the usual J-curve a second independent one emerges. When the two curves are considered in conjunction a wider range of dynamic possibilities including an approximation to an S-curve emerges.

In an empirical study Marwah and Klein (1996) estimate trade balance equations for US and Canada to determine the adjustments in trade balances. They find that there is a tendency for trade balances to worsen first after a depreciation and then to improve, but after several quarters there appears to be a tendency to worsen again, which produces an S pattern that is also suggested by Backus et al. (1994). However Bahmani-Oskoee and Brooks (1999) criticize Marwah and Klein (1996) on the grounds that they use non-stationary data to derive their results.

In this study we will examine the relationship between the trade balance and real exchange rate for the Turkish data, covering the period of 1987(I)-2000(IV). In order to differentiate between the long-run equilibrium and short-run disequilibrium dynamics and also to deal with the non-stationary data, cointegration analysis and a vector error correction model will be used. Also to further investigate the dynamics of the trade balance the generalized impulse response analysis will be used. 
Impulse response analysis investigates the impulse response function through time, which measures the time profile of the effect of a shock at a given point in time on the expected future values of the variables in a dynamical system. Demirden and Pastine (1995) suggest using impulse response analysis in determining the existence of J-curve in the data, which allows for detecting the feedback effects. However their study uses orthogonalized impulse responses, which are not unique, and changes as the ordering of the model variables change. Koop et al (1996) and Pesaran and Shin (1998) developed the method of generalized impulse responses which are unique and invariant to the reordering of the variables in the VAR, and can be used both for the linear and nonlinear models. For this reason we will employ this methodology to analyze the dynamics of the trade balance.

Organization of the paper is as follows: section II introduces the model and the data set that is used in estimations. The cointegration analysis is described in section III. Results of the short-run dynamic analysis within the form of an ECM are given in section IV. Section V presents the impulse response analysis and finally section VI concludes the paper.

\section{Model and Data}

Our dynamic specification is based on the imperfect substitutes model of Goldstein and Khan (1995), where the reduced form of the trade balance is developed by R\&Y and is given as follows:

$$
B=f\left[Y, Y^{*}, q\right] \quad \text { and } \quad q=(P * / P) E
$$

Where $\mathrm{B}$ is the trade balance, $\mathrm{Y}$ domestic income, $\mathrm{Y}^{*}$ foreign income and $\mathrm{q}$ is the real exchange rate, E nominal exchange rate and $\mathrm{P}^{*}$ and $\mathrm{P}$ are the foreign and domestic price levels respectively. The J-curve hypothesis suggests that the partial derivative $\mathrm{dB} / \mathrm{dq}$ will be negative in the short-run and positive in the long-run.

In this study rather than using single equation techniques we will use the VECM approach where we will model equation (1) as follows:

$$
\begin{aligned}
\Delta X_{t} & =\sum_{i=1}^{k-1} \Gamma_{i} \Delta X_{t-i}+\Pi X_{t-k}+\mu+\varepsilon_{t} \\
\Pi & =\alpha \beta^{\prime}
\end{aligned}
$$


Where $X_{t}$ is a px1 vector of stochastic variables, in our case $X_{t}=\left[B, Y, Y^{*}, q\right]$, which are presumed to be $I(1)$. $\mu$ is the intercept term, and $\varepsilon_{t}$ is the error term and, is assumed to be white noise. Since $\mathrm{X}_{\mathrm{t}}$ is presumed to be I(1), if a linear combination of these I(1) variables exists that is stationary then these variables are said to be cointegrated. If cointegration exists then Engle and Granger (1987) showed that an error correction representation like equation (1) exists for these variables. Furthermore $\Pi$ is the impact matrix where $\alpha$ is the vector of adjustment coefficients and $\beta$ is the vector of cointegrating relations and both are $\mathrm{p} x \mathrm{r}$ matrices. Since the existence of error correction form depends on the cointegrating relations we will first search for the long-run cointegrating relations between the variables of the model and then estimate equation (2) and look at the short-run dynamics between these variables of the model.

Our data set covers the period of 1987(I) to 2000(IV) and uses the Turkish data set. Rose (1990)'s data includes the Turkish data for the period 1970-1988 and he finds out that real exchange rate has no effect on the trade balance for that period. Other than Rose (1990) we know no study that is done for the Turkish data set in this respect.

Our variables are the real trade balance B1, which is defined as the difference between the exports and imports in constant 1987 prices. REER2 is the real effective exchange rate, based on the currencies of the two basic trade partners of Turkey which are the US and Germany. REER2 is calculated by using the weighted average of real US Dollar and German Mark exchange rates. Weights used are determined by looking at the weight of these two countries in the Turkish foreign trade, and are 0.3 and 0.7 respectively for USD and DM rates $^{1}$. YSA and W2 are the domestic and foreign income variables. For domestic and foreign real income we have used the GDP index values, for foreign income again a weighted average of the US and German GDP indices are calculated, for domestic income the series is seasonally adjusted All the data used are originally derived from the Central Bank of Republic of Turkey database and IMF-IFS CD-Rom database.

By using this data set we will proceed on estimating an error correction model to examine the dynamics of the trade balance, but first the long-run properties are examined by using the cointegration analysis, in the next section. 


\section{Cointegration Analysis}

At first, time series properties of the model variables are examined by using the augmented DickeyFuller (ADF) unit root tests (Dickey and Fuller, 1981). Results of these tests are summarized in tables 1 and $2^{2}$. Inspection of table 1 shows that all the variables of the model have unit roots. By looking at table 2 we see that they are stationary at first differences. Therefore we have concluded that our variable set is I(1) and carry on investigating the possibility of cointegration among these variables.

Table 1 ADF Tests

\begin{tabular}{|c|c|c|c|c|}
\hline Vars. & Lags & $\eta_{\mu}$ & Lags & $\eta_{\tau}$ \\
\hline B1 & 11 & -1.465 & 11 & -2.146 \\
\hline REER2 & 1 & -2.821 & 1 & -3.294 \\
\hline YSA & 0 & -1.032 & 0 & -3.122 \\
\hline W2 & 0 & -1.431 & 0 & -2.418 \\
\hline
\end{tabular}

Table 2 ADF Tests of the first differences

\begin{tabular}{|c|c|c|c|c|}
\hline Vars. & Lags & $\eta_{\mu}$ & Lags & $\eta_{\tau}$ \\
\hline DB1 & 10 & $-4.564 * *$ & 10 & $-4.494 * *$ \\
\hline DREER2 & 0 & $-5.390^{* *}$ & 0 & $-5.323 * *$ \\
\hline DYSA & 0 & $-7.962 * *$ & 0 & $-7.879 * *$ \\
\hline DW2 & 0 & $-6.107 * *$ & 0 & $-6.150 * *$ \\
\hline ** significance at $99 \%$
\end{tabular}

The cointegration analysis uses the Johansen technique (Johansen, 1995). Initially we determine the rank of the long-run matrix $\Pi$, which involves finding the number of linearly independent columns of $\Pi$. This in fact will give us the number of cointegrating relationships that exist among our variables. Johansen developed two test statistics to determine the cointegration rank; the maximum eigenvalue statistics and the trace statistics. These statistics are calculated for our VAR model ${ }^{3}$ and are given in table 3 . Both of these tests are standard likelihood ratio tests with non-standard distributions ${ }^{4}$. The maximum eigenvalue statistics test that there are $r$ cointegrating vectors against the alternative that $\mathrm{r}+1$ exists. The trace statistics on the other hand test the null of $\mathrm{r}=\mathrm{k}(\mathrm{k}=1,2, \ldots, \mathrm{n}-1)$ against the alternative of unrestricted $\mathrm{r}$.

Table 3 Rank (r) Determination for $\Pi$

\begin{tabular}{|c|c|c|c|c|c|c|c|}
\hline Ho & $\mathbf{H}_{\mathbf{1}}$ & $\begin{array}{c}\text { Max. } \\
\text { Eigenv. }\end{array}$ & $\begin{array}{c}\mathbf{9 5 \%} \text { crit. } \\
\text { value }\end{array}$ & $\mathbf{H o}$ & $\mathbf{H}_{\mathbf{1}}$ & $\begin{array}{c}\text { Trace } \\
\text { stat. }\end{array}$ & $\begin{array}{c}\mathbf{9 5 \%} \text { crit. } \\
\text { value }\end{array}$ \\
\hline $\mathbf{r}=\mathbf{0}$ & $\mathbf{r}=\mathbf{1}$ & $46.24^{* *}$ & 31.79 & $\mathbf{r}=\mathbf{0}$ & $\mathbf{r} \geq \mathbf{1}$ & $84.88^{* *}$ & 63.00 \\
\hline $\mathbf{r} \leq \mathbf{1}$ & $\mathbf{r}=\mathbf{2}$ & 20.77 & 25.42 & $\mathbf{r} \leq \mathbf{1}$ & $\mathbf{r} \geq \mathbf{2}$ & 38.63 & 42.34 \\
\hline $\mathbf{r} \leq \mathbf{2}$ & $\mathbf{r}=\mathbf{3}$ & 10.35 & 19.22 & $\mathbf{r} \leq \mathbf{2}$ & $\mathbf{r} \geq \mathbf{3}$ & 17.87 & 25.77 \\
\hline $\mathbf{r} \leq \mathbf{3}$ & $\mathbf{r}=\mathbf{4}$ & 7.52 & 12.39 & $\mathbf{r} \leq \mathbf{3}$ & $\mathbf{r}=\mathbf{4}$ & 7.52 & 12.39 \\
\hline
\end{tabular}


Table 3 gives the results of the maximum eigenvalue statistics and $95 \%$ critical values on the third and fourth columns and the trace statistics and $95 \%$ critical values on the seventh and eighth columns. Both of these tests indicate that there exists a single cointegration relationship among our four variables.

After determining the cointegration rank we have also tested linear restrictions on $\alpha$ and $\beta$. Given that the rank of $\Pi$ is one, the $\alpha$ and $\beta$ vectors are as follows:

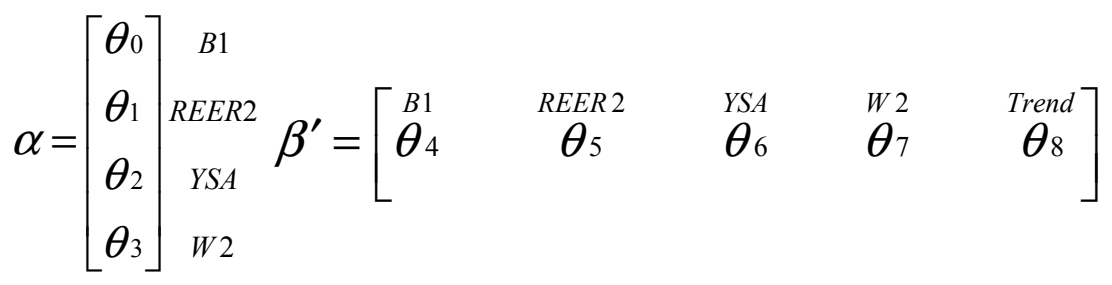

First we will test linear restrictions on $\alpha$, which are the weak exogeneity tests. The condition for $\mathrm{X}_{\mathrm{it}}$ in equation (2) to be weakly exogenous for $\beta$ is that $\Delta X_{i t}$ does not contain information about the long-run parameters $\beta$, and this is achieved if rows of $\alpha$ corresponding to that variable are equal to zero. If a variable is weakly exogenous it means that it is possible to condition the short-run model on that variable without any loss of information, and will provide parsimony. Table 4 summarizes the results of these tests. Our assessment illustrate that weak exogeneity could only be rejected for B1 and REER2; the domestic income and world income variables' weak exogeneity are not rejected with high probability. To further strengthen our result we have also excluded these two variables $\alpha$ coefficients simultaneously and again we found that YSA and W2 are simultaneously weakly exogenous.

Table 4 Weak Exogeneity Tests (Linear restrictions on $\alpha$ )

\begin{tabular}{|c|c|}
\hline Variables & $\beta$ unrestricted, rank $=1$ \\
\hline B1 & $\chi 2(1)=14.277[0.0002]^{* *}$ \\
\hline REER2 & $\chi 2(1)=17.860 \quad[0.0000] * *$ \\
\hline YSA & $\chi 2(1)=0.0543 \quad[0.8157]$ \\
\hline W2 & $\chi_{2}^{2(1)}=0.0616 \quad[0.8039]$ \\
\hline YSA \& W2 & $\chi 2(2)=0.1229 \quad[0.9404]$ \\
\hline
\end{tabular}

** significance at $99 \%$

In order to identify the long-run relationship we have also tried some exclusion tests on $\beta$, which is the cointegration vector. Results of these tests are summarized in table 5. Initially exclusion of every variable from $\beta$ is tested; main conclusion from this experiment is that exclusion of YSA and W2 cannot be rejected. Thus we can conclude that in the long-run real exchange rate is the only variable that determines the trade balance, and 
domestic and foreign incomes have no influence over the trade balance. Finally in the last row of table 5 the result of restrictions on $\beta$ simultaneously with the weak exogeneity restrictions lies, and it can be seen that it is not rejected. Therefore we decide to use this specification for our cointegration vector. This final specification is given in table 6 .

Table 5 General Restrictions on $\Pi$

\begin{tabular}{|c|c|}
\hline Restrictions & LR-tests \\
\hline$\theta_{4}=0$ & $\chi 2(1)=25.416[0.0000]^{* *}$ \\
\hline$\theta_{5}=0$ & $\chi 2(1)=4.1965[0.0405]^{*}$ \\
\hline$\theta_{6}=0$ & $\chi 2(1)=0.1129[0.7369]$ \\
\hline$\theta_{7}=0$ & $\chi 2(1)=3.7852[0.0517]$ \\
\hline$\theta_{8}=0$ & $\chi 2(1)=3.6700[0.0554]$ \\
\hline$\theta_{4}=\theta_{5}=0$ & $\chi 2(2)=30.217[0.0000]^{* *}$ \\
\hline$\theta_{6}=\theta_{7}=0$ & $\chi 2(2)=4.8645[0.0878]$ \\
\hline$\theta_{6}=\theta_{7}=\theta_{8}=0$ & $\chi 2(3)=20.275[0.0001]^{* *}$ \\
\hline$\theta_{2}=\theta_{3}=\theta_{6}=\theta_{7}=0 \& \theta_{4}=1$ & $\chi 2(4)=7.1125[0.1301]$ \\
\hline$*$ significance at $95 \%$ & $* *$ significance at $99 \%$ \\
\hline
\end{tabular}

In table 6 restricted cointegration vector $\beta$, restricted adjustment coefficients vector $\alpha$, and finally restricted long-run matrix $\Pi$ is given. These results show that in the long-run real exchange rate is the main factor that influences the trade balance. Also our cointegration analysis showed that a real depreciation of TL improves the trade balance of Turkey in the long-run.

Table 6 Restricted Long-run Matrices under $\theta_{2}=\theta_{3}=\theta_{6}=\theta_{7}=0$ \& $\theta_{4}=1$

\begin{tabular}{|c|c|c|c|c|c|}
\hline \multicolumn{6}{|c|}{ Standardized $\beta^{\prime}$ eigenvectors } \\
\hline & B1 & REER2 & YSA & W2 & Trend \\
\hline & 1.000 & -1.4419 & 0.000 & 0.000 & 2.5845 \\
\hline \multicolumn{6}{|c|}{ Standardized $\alpha$ coefficients } \\
\hline & & B1 & -0.787 & & \\
\hline & & REER2 & -0.051 & & \\
\hline & & YSA & 0.000 & & \\
\hline & & W2 & 0.000 & & \\
\hline \multicolumn{6}{|c|}{ Restricted long-run matrix $\Pi=\alpha \beta^{\prime}$, rank 1} \\
\hline & B1 & REER2 & YSA & W2 & Trend \\
\hline B1 & -0.7867 & 1.1344 & 0.0000 & 0.0000 & -2.0332 \\
\hline REER2 & -0.0513 & 0.0739 & 0.0000 & 0.0000 & -0.1325 \\
\hline YSA & 0.0000 & 0.0000 & 0.0000 & 0.0000 & 0.0000 \\
\hline W2 & 0.0000 & 0.0000 & 0.0000 & 0.0000 & 0.0000 \\
\hline
\end{tabular}




\section{Error Correction Model}

In this section we have estimated equation (2) by using our cointegration results from section IV. First we have formed the error term of equation (2) by defining a new variable as follows:

\section{$\mathrm{C}=\mathrm{B} 1$ - 1.4419 REEER2 + 2.5845 Trend}

The error correction model then consists of following variables DB1, DEER2 as dependent variables and DYS, DW2 and the error correction term $\mathbf{C}$ as explanatory variables. The variables are differenced to map the system to $\mathrm{I}(0)$, and the model is conditioned on DYS and DW2 by using the weak exogeneity result of the previous section. After reducing the insignificant parameters of the model by using F-tests we have achieved the following reduced form of the error correction model, which is summarized in table 7.

Table 7 Reduced ECM

\begin{tabular}{|c|c|c|}
\hline Coefficients & DB1 & DREER2 \\
\hline DB1_1 & $-0.7054(-5.25)^{* *}$ & $-0.0191(-2.27)^{*}$ \\
\hline DB1_2 & $-0.8393(-5.72)^{* *}$ & $-0.0224(-2.44)^{*}$ \\
\hline DREER_2 & $5.2551(2.45)^{*}$ & $-0.2318(-1.73)$ \\
\hline DYSA_1 & $-8.0897(-3.71)^{* *}$ & $0.0192(0.14)$ \\
\hline C_3 & $-0.7608(-4.44)^{* *}$ & $-0.0480(-4.47)^{* *}$ \\
\hline Constant & $-111.70(-4.06)^{* *}$ & $-7.5398(-4.38)^{* *}$ \\
\hline $\begin{array}{c}\text { Corr. of actual \& } \\
\text { fitted }\end{array}$ & 0.7213 & 0.5693 \\
\hline $\begin{array}{r}* \\
\text { * significance at } 95 \%\end{array}$ & \\
\hline
\end{tabular}

By looking at table 7 it can be seen that in the short-run the foreign income variable is not included in the model since both the first and the second lags are found to be highly insignificant in both equations and exclusion of them is not rejected. Therefore we have concluded that it has no affect on the trade balance, or on the real exchange rate in the short-run as well as in the long-run. The trade balance equation shows that in the short-run besides the autoregressive terms, the real exchange rate and the domestic income are the main determinants of the trade balance. Even though the domestic income has no influence over the trade balance in the long-run, it can be seen that an increase in the domestic income reduces the trade balance in the short-run, as predicted by the theory. When we take a look at the affect of real exchange rate on the trade balance equation we see that the lagged real exchange term is only significant at $95 \%$. We have also tested the exclusion of this term and this test results as $\chi^{2}(1)=6.3822$ which has a probability value of 0.0115 so it was rejected at $98.8 \%$. This shows that in the short-run a real depreciation will cause an improvement in the trade balance. Of course most of the J-curve studies simply look at this result and would conclude that there is no J-curve effect. However we believe that it is still early to decide about the existence of a J-curve effect without considering the feedback effects of the system.

For that we have to also take a look at the exchange rate equation and in the next section we will further take a look at the impulse responses of the error correction model. When we look at the second equation of the ECM we see that there is feedback between the trade balance and the real exchange rate since the lagged trade balance terms influence the real exchange rate equation. In the short-run an improvement in the trade balance 
would cause a real appreciation of the TL. In terms of the real exchange rate equation we see that DB1 and the error correction term, $\mathbf{C}$ are the only significant variables and thus domestic and foreign incomes have no effect on the real exchange rate in the short-run. The feedback between the trade balance and the real exchange rate is such that a real depreciation would improve the trade balance, which in turn would cause a real appreciation; this would cause a worsening in the trade balance, which would cause a real depreciation. Therefore we would expect to see a cyclical pattern when we look at the time profiles of the trade balance and the real exchange rate. We will come back to this issue in the next section.

Again by looking at table 7 we see that the estimated ECM models error correction coefficients of both equations are significant and consistent with the $\alpha$ coefficients estimated during the cointegration analysis of section III. Our error correction terms are both less than zero which implies that there will be a short-run adjustment towards the long-run equilibrium value.

Table 8 Diagnostic Tests of the reduced model

\begin{tabular}{|c|c|c|}
\hline & DB1 & DREER2 \\
\hline AR 1- 4 F $(4,43)$ & $0.1328[0.9695]$ & $0.4216[0.7922]$ \\
\hline Normality $\chi 2(2)$ & $1.1002[0.5769]$ & $15.717[0.0004]^{* *}$ \\
\hline ARCH 1-4 F( 4, 39) & $0.4724[0.7556]$ & $0.2639[0.8993]$ \\
\hline Hetero $\mathrm{F}(\mathbf{1 0}, \mathbf{3 6})$ & $1.2228[0.3100]$ & $1.3124[0.2611]$ \\
\hline Hetero-X F(20,26) & $0.9550[0.5357]$ & $0.7549[0.7382]$ \\
\hline \multicolumn{3}{|c|}{ Vector Tests } \\
\hline \multicolumn{2}{|c|}{ AR 1- 4 F $(16,76)$} & $1.0481[0.4186]$ \\
\hline \multicolumn{2}{|c|}{ Normality $\chi 2(4)$} & $17.806[0.0013]^{* *}$ \\
\hline \multicolumn{2}{|c|}{ Hetero $F(30,100)$} & $1.2742[0.1868]$ \\
\hline \multicolumn{2}{|c|}{ Hetero-X F(60,72) } & $1.1974[0.2312]$ \\
\hline
\end{tabular}

Finally, in table 8 diagnostics tests of the ECM are given ${ }^{5}$. These show that neither the individual equations nor the model as a whole suffer from autocorrelation or heteroscedasticity. It appears that our second equation suffers from non-normality, and that problem is also apparent in the vector test too. We have also checked the stability of the model by looking at break-point recursive Chow tests, which are plotted in figure 1 . This figure shows that all break-point Chow tests lie within the 1\% band, and hence non of them are significant. Thus, parameter constancy cannot be rejected.

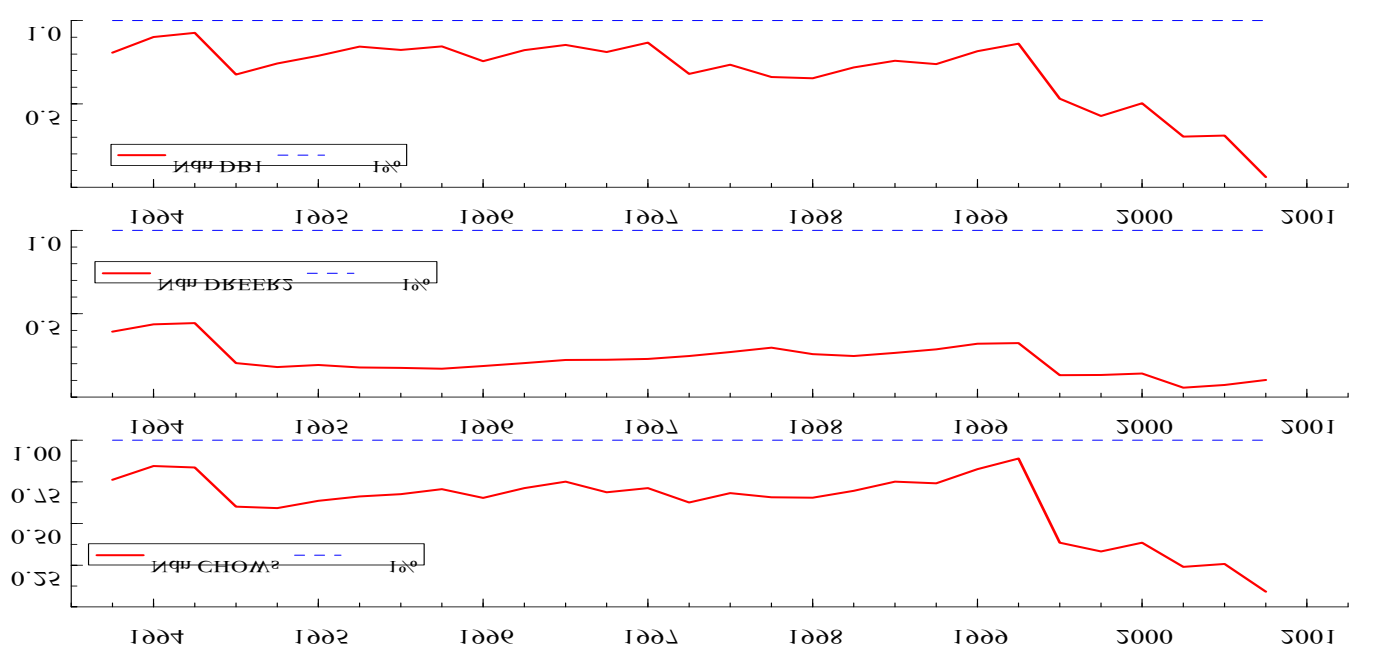

Figure 1 Parameter constancy; Break-point Chow tests 


\section{Impulse Response Analysis}

Impulse response analysis involves measuring the effect of shocks at a point in time on the expected future values of the variables of the dynamic system through time. Thus the idea is similar to the Keynesian multiplier analysis as suggested by Koop et al. (1996) and would include the feedback effects. The classical impulse response analysis uses orthogonalized impulse responses where underlying shocks to the VAR system are orthogonalized using Cholesky decomposition. The problem with this approach is that impulse responses are not unique and they are not invariant to the ordering of the variables in the VAR. This problem can be dealt by imposing a priori restrictions so that covariance matrix is diagonal. These structural restrictions could have theoretical justification in some cases but it is not always possible to justify a particular set of restrictions. Koop et at (1996) and Pesaran and Shin (1998) suggest generalized impulse response analysis as an alternative method in which impulse responses would be unique and invariant to the ordering of the variables. Generalized impulse responses are constructed as an average of present and the past, and the baseline for impulse responses is defined as the conditional expectations based on the history.
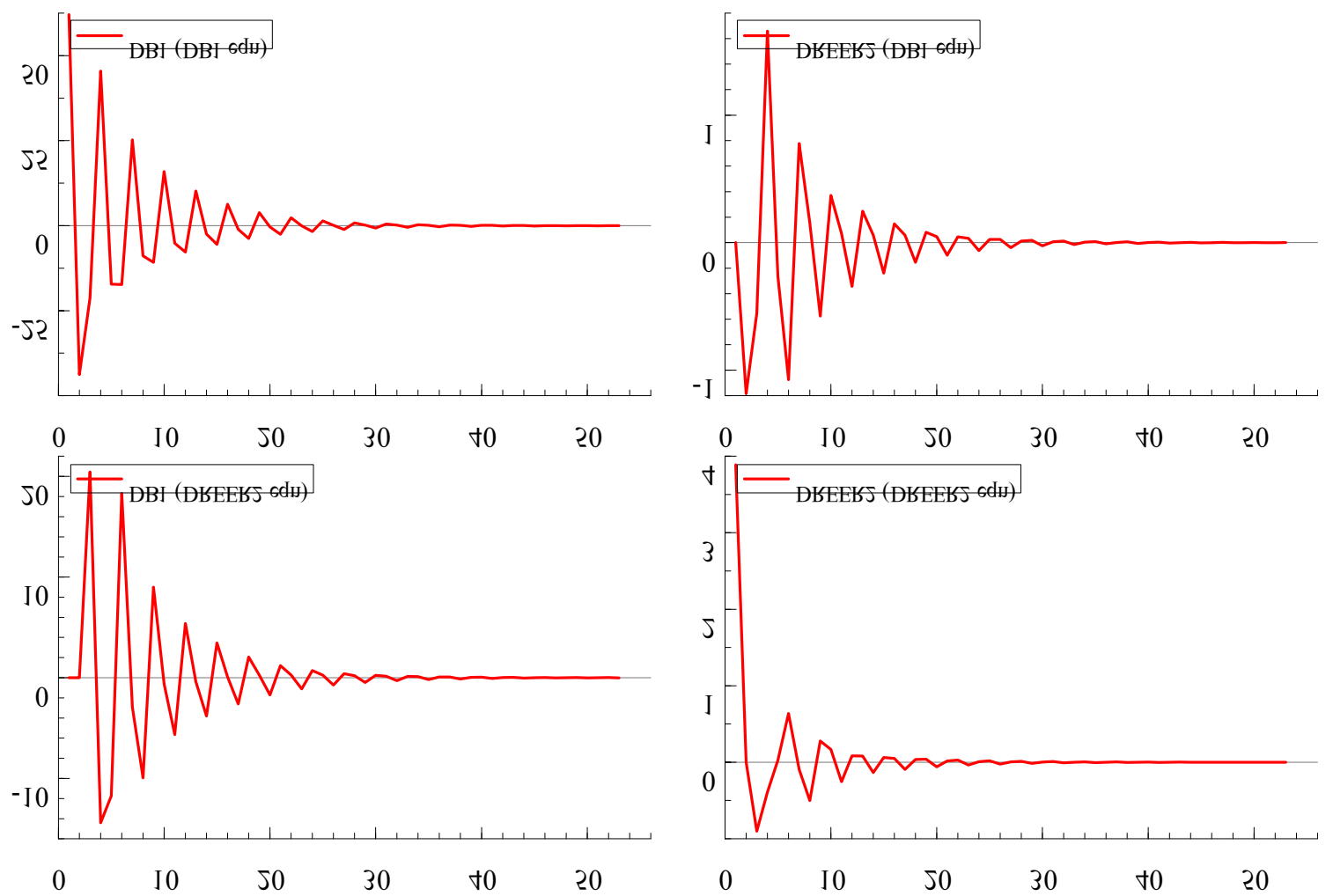

Figure 2 Generalized Impulse Responses 
Here we will take a look at the generalized impulse responses of the ECM estimated in section IV. The generalized impulse responses are plotted in figure 2. These show the impact of one standard error shocks in the DB1 equation and REER2 equation respectively. Here we can determine how the system will respond to a shock in the exchange rate equation, and specifically by looking at the time profile of responses of the trade balance equation we can conclude about the suitability of the J-curve hypothesis to this particular data set. If the J-curve hypothesis were correct we would expect to see an initial decline in the responses of the trade balance in response to a shock in the exchange rate and a later improvement to complete the J-curve behavior. However our findings show that we do not exactly see this pattern when we look at the impulse responses of DB1 as a response to a shock in REER2 equation. Rather what we observe is an initial improvement, then a worsening and an improvement and so on. Thus a cyclical pattern emerges which approximately dies out in 20 quarters. This is the feedback effect that we have also explained in section IV.
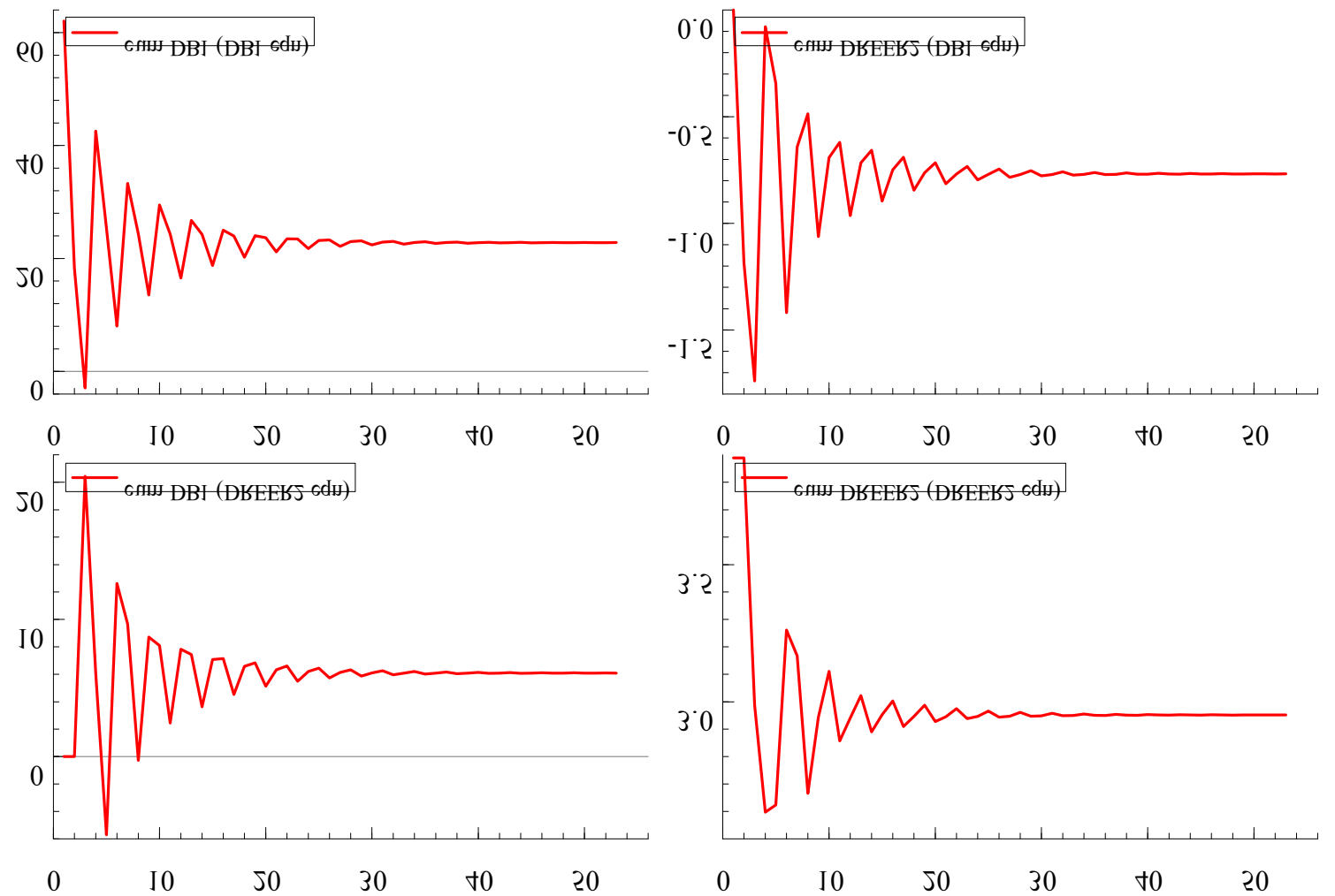

Figure 3 Cumulative Generalized Impulse Responses

Figure 3 plots the cumulative impulse responses of the shocks in trade balance equation and the real exchange rate equation respectively. These show that the cumulative effect of a real exchange rate shock improves the trade balance. In line with the feedback that we have observed in the ECM a trade balance shock appreciates the real exchange rate. 
The cyclical pattern observed here is reminiscent of the findings of Marwah and Klein (1996) for the US and Canadian data, where they found that there is a tendency for trade balance to worsen first after a depreciation and then to improve, but after several quarters there appears to be a tendency to worsen again for both the US and Canada. Backus et al (1994) also talk about the S shaped response of the trade balance to the changes in terms of trade. Similarly Roberts (1995) talks about possibility of an S-curve to emerge in terms of trade account dynamics.

\section{Conclusion}

Here we have studied the short-run and long-run behavior of the trade balance and real exchange rate in a dynamic model. First of all cointegration analysis showed that as opposed to R\&Y, Rose (1990) and (1991) for Turkish data there is a long-run relationship between the trade balance and the real exchange rate, and as the economic theory suggests in the long-run a real depreciation of TL improves the Turkish trade balance. We have also found that in the long-run neither domestic, nor foreign incomes have an effect on the trade balance.

In search for the J-curve in the Turkish data we have also looked at the short-run dynamics by using an ECM. The short-run model indicated that there is feedback between the trade balance and the real exchange rate and this feedback is in such a way that it suggests a cyclical pattern in terms of the responses of the trade balance to a real depreciation. However we can also say that our analysis doesn't find an evidence of the short-run worsening of trade balance implied by the j-curve hypothesis.

Finally the impulse response analysis is also supported the cyclical feedback pattern implied by the ECM. From the impulse response analysis we have concluded that a real exchange rate shock will initially improve then worsen and then improve the trade balance. This cyclical pattern dies out in approximately 5 years time. This pattern does not support the classical $\mathrm{J}$ curve hypothesis of the literature but is in line with the newly suggested S-curve pattern of Backus et al (1994). 


\section{References}

Backus, D.K., Kehoe P.J. and Kydland F.E., (1994) Dynamics of the trade balance and the terms of trade: the Jcurve?, American Economic Review, 84(1), 84-103.

Bahmani-Oskooee M. and Brooks T.J., (1999) Bilateral J-curve between US and her trading partners, Weltwirtschaftliches Archiv, 135(1), 156-165.

Demirden T. and Pastine I., (1995) Flexible exchange rates and the J-curve: an alternative approach, Economic Letters, 48, 373-377.

Dickey, D. A. and Fuller W. A. (1981) Likelihood ratio statistics for autoregressive time series with a unit root, Econometrica, 49, 1057-72.

Doornik J.A. and Hansen H., (1994) A practical test for univariate and multivariate normality, Discussion paper, Nuffield College.

Engle,R.F. and Granger C.W.J., (1987) Cointegration and error correction: Representation estimation and testing, Econometrica, 55, 251-276.

Johansen, S., (1995) Likelihood-Based Inference in Cointegrated Vector Autoregressive Models, (Oxford, Oxford University Press).

Koray F. and McMillin W.D., (1999) Monetary shocks, the exchange rate, and the trade balance, Journal of International Money and Finance, 18, 925-940.

Koop G., Pesaran M.H. and Potter S.M., (1996) Impulse response analysis in nonlinear multivariate models, Journal of Econometrics, 74, 119-147.

Krugman P.R and Baldwin R.E., (1987) The persistence of the U.S. trade deficit, Brookings Papers on Economic Activity, 1, 1-43.

Leonard G. and Stockman A.C., (2001) Current accounts and exchange rates: a new look at the evidence, NBER working paper no:8361.

Marwah K. and Klein L.R., (1996) Estimation of J-curves: United States and Canada, Canadian Journal of Economics, 29(3), 523-539.

Osterwald-Lenum M., (1992) A note with quintiles of the asymptotic distribution of the ML cointegration rank test statistics, Oxford Bulletin of Economics and Statistics, 54, 461-72. 
Pesaran H.H and Shin Y., (1998) Generalized impulse response analysis in linear multivariate models, Economics Letters, 58, 17-29.

Roberts M.A., (1995) The second J-curve and trade account dynamics, Applied Economics Letters, 2, 31-33. Rose A.K. and Yellen J.L., (1989) Is there a J-curve?, Journal of Monetary Economics, 24, 53-68.

Rose A.K., (1990) Exchange rates and the trade balance: some evidence from developing countries, Economic Letters, 34, 271-275.

Rose A.K., (1991) The role of exchange rates in a popular model of international trade: does the Marshall-Lerner condition hold?, Journal of International Economics, 30, 301-316.

Singh T., (2002) India's trade balance: the role of income and exchange rates, Journal of Policy Modeling, in press.

White H., (1980) A heteroscedastic-consistent covariance matrix estimator and a direct test for heteroscedasticity, Econometrica, 48, 817-838.

Wilson P. and Tat K.C., (2001) Exchange rates and the trade balance: the case of Singapore 1970-1996, Journal of Asian Economics, 12, 47-63. 


\section{Endnotes}

${ }^{1}$ We have also calculated another set of real effective exchange rate series based on the weights used by the State Planning Organization and the Central Bank of Republic of Turkey, which are 0.75 and 0.25 respectively for USD and DM rates. When we used this alternative exchange rate series we have seen that the results based on this variable does not show much discrepancy in terms of our conclusions, however it gives worse fit. Those results are available upon request.

${ }^{2}$ Lag length for the ADF tests are selected by looking at the Akaike Information Criteria, and the sequential Ftests.

${ }^{3}$ To determine the order of the VAR model sequential F-tests starting from lag length of 5 are used. Besides for each model the diagnostics of the VAR is also checked and a lag length of 3 is found appropriate for this data set.

${ }^{4}$ Critical values are based on a response surface fitted to the results of Osterwald -Lenum (1992) for different specifications of trend and constant terms.

5 The diagnostics tests reported in table 8 are an LM test for auto correlation, with the null of no autocorrelation, test of normality based on Doornik and Hansen (1994), an LM test for ARCH, and a test for heteroscedasticity based on White (1980), and the vector versions of those. 